\title{
Applicability of the WHO maternal near miss tool in sub-Saharan Africa: a systematic review
}

\author{
Abera Kenay Tura ${ }^{1,2^{*}}$ (D) To Lam Trang ${ }^{3}$, Thomas van den Akker ${ }^{4}$, Jos van Roosmalen ${ }^{4,5}$, Sicco Scherjon ${ }^{2}$, \\ Joost Zwart ${ }^{6}$ and Jelle Stekelenburg ${ }^{3,7}$
}

\begin{abstract}
Background: Applicability of the World Health Organization (WHO) maternal near miss criteria in low-income settings is not systematically addressed in the literature. The objective of this review was to determine the applicability of the WHO maternal near miss tool in sub-Saharan Africa.

Methods: We searched PubMed, Embase, Popline, CINAHL, AJOL, and Google scholar using key words for maternal near miss and sub-Saharan Africa. Studies which applied the WHO maternal near miss criteria, containing clear definitions, and published between January 1st, 2009 and December 31st, 2017 were included. Two authors independently extracted data. Quantitative analysis and narrative synthesis were conducted, and medians with interquartile range (IQR) were calculated for summarizing the findings. Methodological quality of the studies was assessed using the Estabrook's quality assessment and validity tool.

Results: Fifteen studies from nine countries comprising 227,077 participants were included. Median maternal near miss ratio was 24.2 (IQR: 12.4-35.8) per 1000 live births ranging from 4.4 in a population-based study in South Africa to 198 in a rural private hospital in Nigeria. Eight studies reported challenges in implementing the WHO maternal near miss tool, especially related to the threshold for blood transfusion, and availability of several laboratory-based criteria. In three studies, local adaptations were made.
\end{abstract}

Conclusion: This review showed that the WHO maternal near miss tool is not uniformly applied in sub-Saharan Africa. Therefore, a common adaptation for the region is required to increase its applicability.

Keywords: Systematic review, Severe acute maternal morbidity, Maternal near miss, Severe maternal outcomes, Sub-Saharan Africa

\section{Background}

With the decline of maternal deaths, studying maternal near misses (MNM) has been used as a proxy to measure quality of obstetric care $[1,2]$. MNM refers to a very ill pregnant or delivered woman who nearly died but survived a complication during pregnancy, childbirth or within 42 days of termination of pregnancy [3]. Studying MNM has additional advantages to studying maternal

\footnotetext{
* Correspondence: a.k.tura@umcg.nl

${ }^{1}$ School of Nursing and Midwifery, College of Health and Medical Sciences, Haramaya University, Dire Dawa, Ethiopia

${ }^{2}$ Department of Obstetrics and Gynecology, University Medical Centre Groningen, University of Groningen, Hanzeplein 1, 9700 RB, P.O.B, 30001 Groningen, The Netherlands

Full list of author information is available at the end of the article
}

deaths since it occurs more often, shares similar characteristics with deaths and is less 'threatening' to report by health providers and managers, possibly reducing underreporting $[1,4,5]$. In addition, audit of MNM brings the possibility to include opinions and perceptions of the women themselves, who may be interviewed after the event $[6,7]$.

A WHO maternal morbidity-working group developed MNM criteria in 2009 mainly focusing on presence of organ dysfunction [3]. The WHO near-miss approach was published in 2011 to serve as a manual for conducting MNM studies [6]. The manual provides guidelines to implement MNM studies (including definition of terms and expected results), calculations of MNM indicators, a

(c) The Author(s). 2019 Open Access This article is distributed under the terms of the Creative Commons Attribution 4.0 International License (http://creativecommons.org/licenses/by/4.0/), which permits unrestricted use, distribution, and reproduction in any medium, provided you give appropriate credit to the original author(s) and the source, provide a link to the Creative Commons license, and indicate if changes were made. The Creative Commons Public Domain Dedication waiver (http://creativecommons.org/publicdomain/zero/1.0/) applies to the data made available in this article, unless otherwise stated. 
data collection tool, and dummy tables, as well as guidance for interpretation. The MNM identification criteria consist of 25 parameters grouped into clinical, laboratory, and management-based criteria mainly focusing on presence of organ dysfunction-cardiac, respiratory, renal, coagulation/ hematological, hepatic, neurologic, and uterine dysfunctions (Table 1). Although the WHO MNM tool has been widely used, including in low-income settings, the tool turned out to be rather difficult to apply because of limited applicability especially the laboratory- and management-based criteria in low-income settings [8-10]. Therefore, several authors suggested local adaptations $[9$, 11], noted the need for practical MNM criteria for use in low-resource settings [8].

Systematic reviews have indicated that the use of different sets of criteria was one of the major limitations in estimating the burden of MNM, hampering comparisons between settings and countries [12-14]. Despite WHO's recommendation to use a uniform set of clinical, laboratory-, and management- based criteria for MNM identification [3], classifications based on only disease-based criteria are still being applied in several studies [15]. Any recommendations to apply either the WHO MNM criteria or resorting to adaptations for low-resource settings should be based on knowledge of performance of

Table 1 World health organization maternal near miss criteria [3]

\begin{tabular}{|c|c|}
\hline \multicolumn{2}{|l|}{ Clinical criteria } \\
\hline Acute cyanosis & Loss of consciousness lasting $>12 \mathrm{~h}$ \\
\hline Gasping & $\begin{array}{l}\text { Loss of consciousness and absence } \\
\text { of pulse/heart beat }\end{array}$ \\
\hline $\begin{array}{l}\text { Respiratory rate }>40 \text { or }<6 / \\
\text { min }\end{array}$ & Stroke \\
\hline Shock & Uncontrollable fit/total paralysis \\
\hline $\begin{array}{l}\text { Oliguria non-responsive to fluids } \\
\text { or diuretics }\end{array}$ & $\begin{array}{l}\text { Jaundice in the presence of pre- } \\
\text { eclampsia }\end{array}$ \\
\hline \multicolumn{2}{|l|}{ Clotting failure } \\
\hline \multicolumn{2}{|l|}{ Laboratory-based criteria } \\
\hline $\begin{array}{l}\text { Oxygen saturation }<90 \% \text { for } \\
\geq 60 \text { min }\end{array}$ & $\mathrm{pH}<7.1$ \\
\hline $\mathrm{PaO} 2 / \mathrm{FiO} 2<200$ mmHg & Lactate $>5$ \\
\hline $\begin{array}{l}\text { Creatinine } \geq 300 \mathrm{mmol} / / \text { or } \\
\geq 3.5 \mathrm{mg} / \mathrm{d} \bar{l}\end{array}$ & $\begin{array}{l}\text { Acute thrombocytopenia }(<50,000 \\
\text { platelets) }\end{array}$ \\
\hline $\begin{array}{l}\text { Bilirubin }>100 \mathrm{mmol} / / \mathrm{l} \text { or } \\
>6.0 \mathrm{mg} / \mathrm{dl}\end{array}$ & $\begin{array}{l}\text { Loss of consciousness and the } \\
\text { presence of glucose and ketoacids } \\
\text { in urine }\end{array}$ \\
\hline \multicolumn{2}{|l|}{ Management-based criteria } \\
\hline $\begin{array}{l}\text { Use of continuous } \\
\text { vasoactive drugs }\end{array}$ & $\begin{array}{l}\text { Intubation and ventilation for } \geq 60 \\
\text { min not related to anesthesia }\end{array}$ \\
\hline $\begin{array}{l}\text { Hysterectomy following } \\
\text { infection or hemorrhage }\end{array}$ & Dialysis for acute renal failure \\
\hline $\begin{array}{l}\text { Transfusion of u5 units red } \\
\text { cell transfusion }\end{array}$ & $\begin{array}{l}\text { Cardio-pulmonary resuscitation } \\
\text { (CPR) }\end{array}$ \\
\hline
\end{tabular}

available criteria and pay attention to challenges that may occur during their implementation. Aim of this review was to assess applicability and challenges related to use of the WHO MNM tool in sub-Saharan Africa.

\section{Methods}

The review was conducted according to the Preferred Reporting Items for Systematic reviews and Meta-Analysis (PRISMA) guideline [16]. The review protocol was registered in PROSPERO (CRD42015023883). PubMed, Embase, Popline, CINHAL, and AJOL databases were searched using key terms developed in consultation with a medical information specialist librarian of the University Medical Centre Groningen. We used the key terms 'near miss', 'severe acute maternal morbidity', 'severe maternal morbidity' in combination with terms used to describe sub-Saharan African region (Additional file 1). Open grey sources and references of identified articles were also searched for additional publications. The search was updated on December 28, 2018.

All identified articles were exported to Refworks reference manager and duplicates removed. Two reviewers (AKT and TLT) independently screened titles and abstracts of the studies. All potentially relevant articles and articles that could not clearly be excluded on the basis of the abstract only were retained for full text review. Differences between assessors to include articles in full text review were resolved by a senior reviewer (JS). Abstract and full text screening were conducted online using Covidence (www.covidence.org) [17]. Studies were included in the review if conducted in sub-Saharan Africa; provided a clear definition of MNM and used the WHO MNM criteria (or adaptations); were published between January 1, 2009 and December 31, 2017; used defined denominators (live births or deliveries); and contained data on frequency of MNM. Also included were studies that contained qualitative data of relevance to assessing the use of the tool, in line with the objective of this review. Studies that did not apply the WHO MNM criteria or that provided no primary data i.e. conference abstracts, reviews, and case reports were excluded. Qualitative studies were excluded since their main focus is mainly on description of the MNM experience: quality of life, risk of complications after MNM, social or economic impacts or experience of women regarding their treatment or complications [18-24]. The year 2009 was chosen as the initial year of inclusion, since this was the year of publication of the 2009 WHO MNM tool and 2017 was the most recent year at the time our search was conducted. AKT and TLT collected data on study design, study settings, data collection period, denominators, number of participants, MNM, maternal deaths, and qualitative data related to applicability or adaptation of the criteria. Data were extracted online using a 
systematic review data repository (srdr.ahrq.gov) platform [25]. Conflicts during data collection were resolved by discussion until unanimity was reached.

One author (AKT) assessed the methodological quality of all studies using Estabrook's quality assessment and validity tool for cross sectional studies [26, 27]. Estabrook's quality assessment and validity tool, developed based on the Cochrane collaboration guidelines, has been widely used for assessing methodological quality of cross-sectional studies [26, 27]. The tool contains a maximum of 16 points and comprises three core areas: sampling, measurement, and statistical analysis. Each item contains a one-point score (0 or 1) except two items (representativeness and matching) containing scores from 0 to 2. A final score for each study was derived using the scoring system developed by de Vet et al [28] by dividing the total score obtained by total points possible after subtracting total number of not applicable (16-not applicable), resulting in a final score between 0 and 1. Each study was then classified as weak $(<0.5)$, moderately-weak (0.51-0.65), moderately-strong (0.66$0.79)$, or strong $(>0.80)$.

Reported challenges related to the use of the WHO MNM tool and qualitative remarks about the applicability of the tool were synthesized using texts and tables. Medians with interquartile range were used to present MNM ratio, maternal mortality ratio (MMR) and mortality index
(MI). We calculated MNM ratio (MNM cases per 1000 live births), MMR (maternal deaths per 100,000 live births) and mortality index (maternal deaths divided by the sum of maternal deaths and MNM). These MNM indicators are essential components of MNM studies and give an indication of the performance of the MNM tool and the quality of care in a particular context [6].

\section{Results}

\section{General description of studies}

A total of 710 citations were identified through our initial search. After removal of duplicates and screening of titles and abstracts, 82 articles were retained for full text review, of which 67 were excluded. Main reasons for exclusion were that the studies did not contain data on MNM (18), did not report any relevant data (16), did not apply the WHO MNM criteria (12) or were duplicate publications from the same database (8) (Fig. 1).

Methodological quality of the remaining 15 studies is shown in Table 2. Matching in design and appropriate handling of missing data were not applied in all studies. Overall, four studies were rated as strong [29-32], three as moderately-strong [33-35] and eight as moderately-weak [11, 36-42].

All studies were cross sectional in design, although sometimes reported as being prospective or retrospective cohort studies. The median MNM ratio was 24.2 per

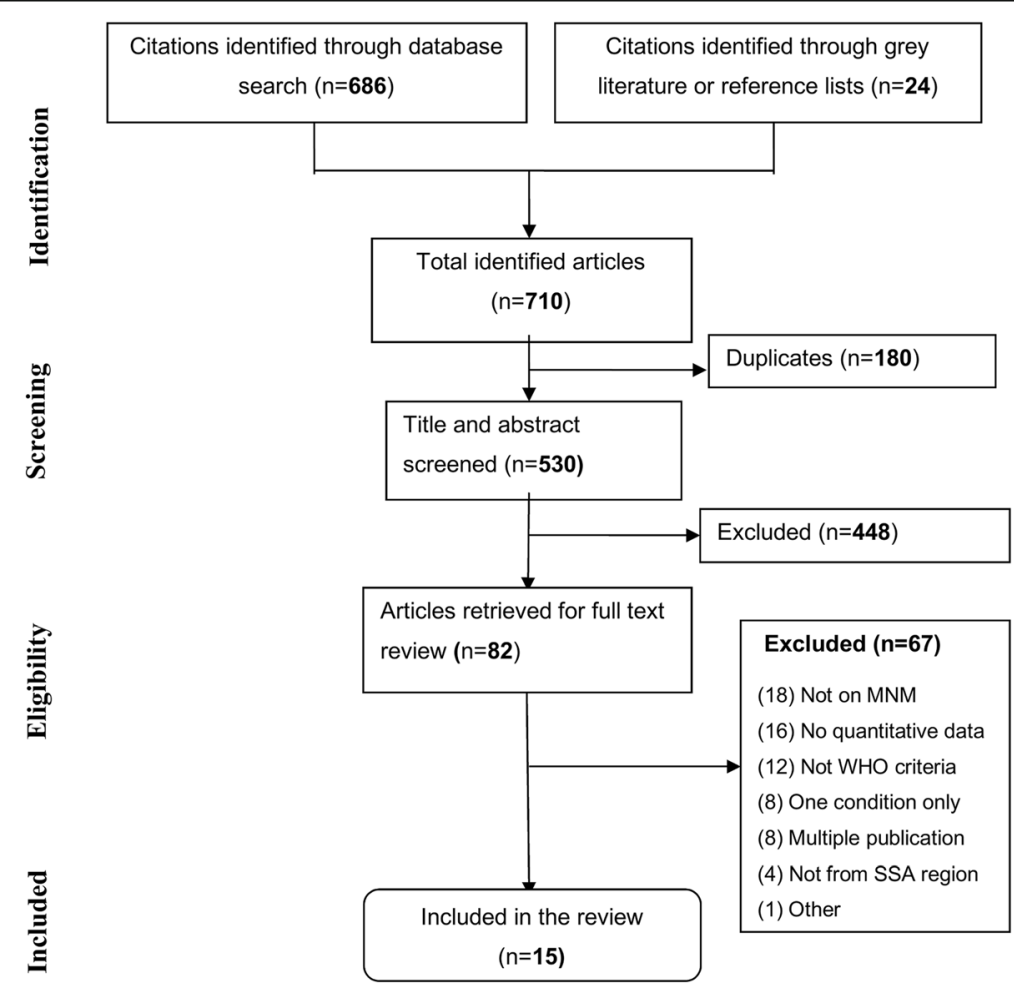

Fig. 1 PRISMA flow chart of the overall phases of the systematic review [16] 


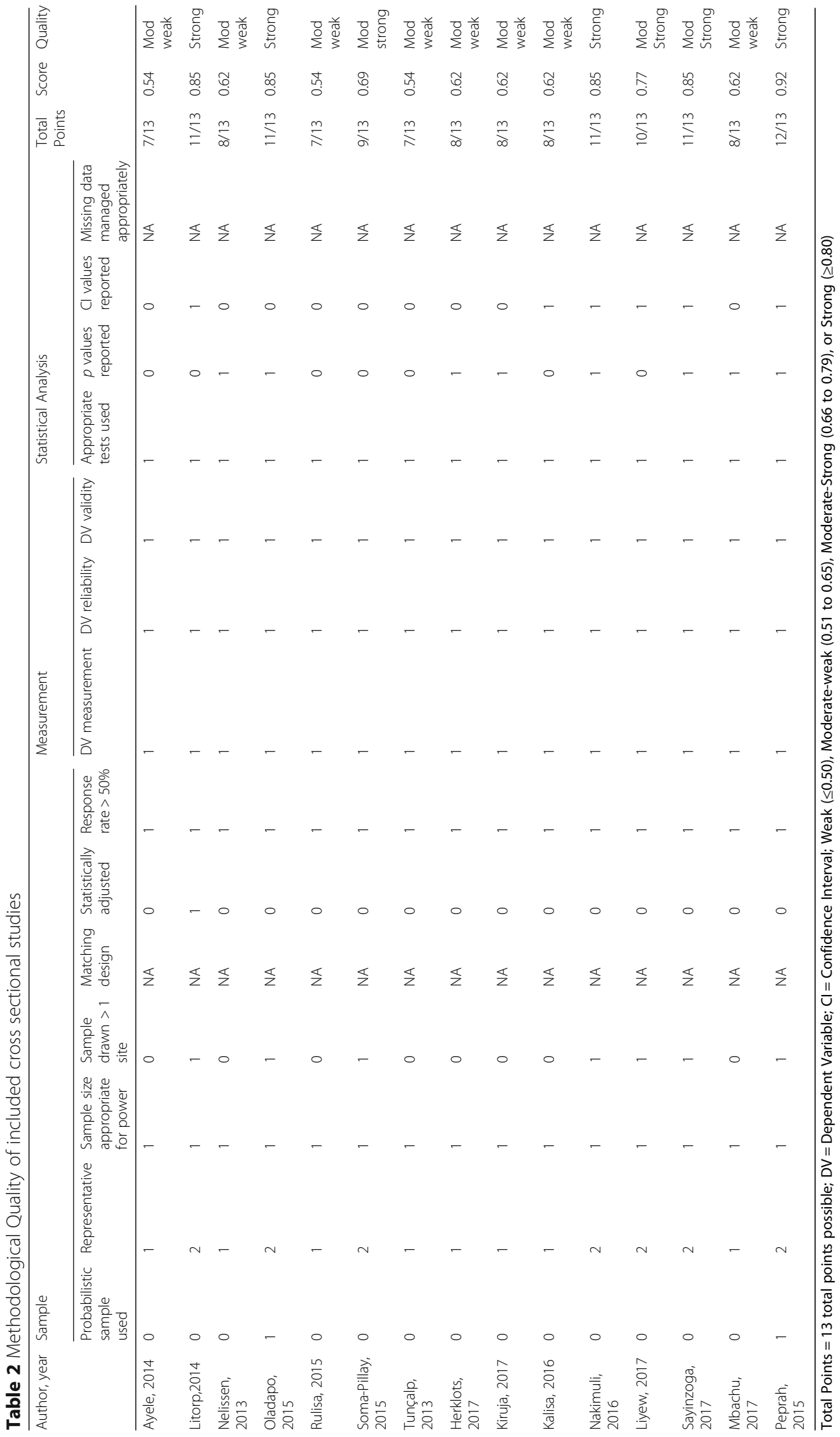


1000 live births and ranged from 4.4 in a population-based study from South Africa to 198 per 1000 live births in a private rural referral hospital in Nigeria. For each maternal death, 6.2 MNM cases were reported ranging from 1.3 in Zanzibar to 15.4 in Rwanda (IQR 2.6-6.8). Mortality index ranged from 6\% in Rwanda to $43 \%$ in Zanzibar with a median of 14 (IQR 12.9-27.7). The maternal mortality ratio ranged from 71 in South Africa to 2875 per 100,000 live births in Rwanda (Table 3).

\section{Applicability of the WHO MNM criteria}

Eight studies discussed challenges related to using the WHO MNM criteria [11, 29, 34, 36-40]. A thorough discussion and adaptation was done in one study (Haydom near miss criteria) [37], and another study utilized these adapted criteria [34]. The Haydom criteria adapted the WHO MNM tool to a local hospital in Tanzania, Haydom Hospital. These criteria comprised of all the WHO clinical-based $(n=11)$, two out of eight laboratory-based criteria, and three out of six management-based criteria of the 2009 WHO MNM criteria. Additional criteria (admission to intensive care unit, eclampsia, sepsis/severe systemic infection, and uterine rupture), which were not part of the 2009 WHO criteria, were added and the threshold for the number of units of blood transfusion was lowered from five or more units of blood to one or more [9]. A study by Kalisa et al. reported another adaptation applied in Rwanda (the Ruhengeri Hospital criteria). In this adaptation they included all the WHO clinical criteria $(n=11)$, four out of eight laboratory-based criteria, and five out of six management-based criteria from the 2009 WHO MNM criteria. Additionally, admission to an intensive care unit, eclampsia, sepsis/severe systemic infection, and uterine rupture [11] were included. The remaining studies reported limitations with the use of some managementbased (dialysis for acute renal failure, use of continuous vaso-active drugs) and a majority of the laboratory- based criteria (measuring $\mathrm{pH}$, lactate, bilirubin, creatinine, arterial blood gas $\mathrm{PaO} 2 / \mathrm{FiO} 2$ ) [29, 36, 38-40] (Table 4). Seven studies did not describe limitations with regard to the use of the WHO MNM tool [30-33, 35, 41, 42]. In general, suggested changes in near miss inclusion criteria included lowering the threshold of units of blood given for transfusion from five or more units to one or more [34, 37], four or more [32] or five or more units ordered but not transfused due to shortage [40]. Criteria that were suggested to be included were additional clinical criteria (eclampsia, uterine rupture, and sepsis or severe systemic infections) $[11,34,37,38]$; and including admission to an intensive care unit as additional management-based criterion [11, 32, 34, 37, 38]. One study compared the WHO criteria with the Sequential Organ Failure Assessment (SOFA) score [43] and reported better utility of the WHO criteria in obstetrics [32]. SOFA is used to quantify organ dysfunction and predict prognosis of severely ill patients [44, 45]. Utility of SOFA score in women with MNM or admitted to intensive care unit was previously validated [43, 46, 47]. Details of reported limitations and suggested adaptations are summarized in Table 4.

\section{Discussion}

This review was conducted to assess the applicability of the WHO MNM criteria and related methodological challenges in sub-Saharan Africa. Eight of the 15 studies indicated presence of challenges in using the WHO MNM criteria: especially related to laboratory- and management-based criteria. Such limitations resulted in adapting and using 'locally applicable' criteria [9, 11, 34] by some while others are opting to use the original criteria [29].

Using the WHO MNM criteria without adaptation is preferred by those who aimed for comparing findings with other studies [29], but fear of underestimation lead others to adapt to broader criteria, hampering comparisons but possibly leading to more genuine estimation of MNM prevalence [9]. Unless standard criteria for using the WHO MNM approach in low-resource settings is developed [48], adaptations by some, while others opt not to adapt, will result in confusion on the outcome of studies and their comparability. Although adaptation to a local context is required for improving obstetric care and for producing genuine MNM estimates [6], several adaptations may further complicate MNM studies. On the other hand, one of the main reasons for using the standard WHO criteria-comparability-should consider issues of under-reporting and feasibility especially in low-income settings [8]. Therefore, there should be MNM criteria which can be uniformly applied and at the same time applicable to create a balanced trade-off [49].

Compared to studies using disease-based criteria, a high mortality index was reported in our review. This shows that the WHO criteria only picked the most severe MNM cases. For example, the studies from Zanzibar (mortality index, 43\%) and Nigeria (mortality index, $40.8 \%)$ reported only 1.3 and 1.5 near misses per maternal death respectively $[30,40]$. Other studies conducted during the same period using disease-specific criteria, reported much higher MNM ratios and lower mortality indices [50-52]. Although most MNM could be identified by clinical or management-based criteria [39], the WHO MNM criteria failed to identify nearly two-thirds of sustained severe acute maternal morbidity and one-third of maternal deaths even in high-income settings [53].

Some notable challenges should be considered in using the WHO MNM criteria in low-income settings: lack of blood for transfusion [54-56] and absence of infrastructure 


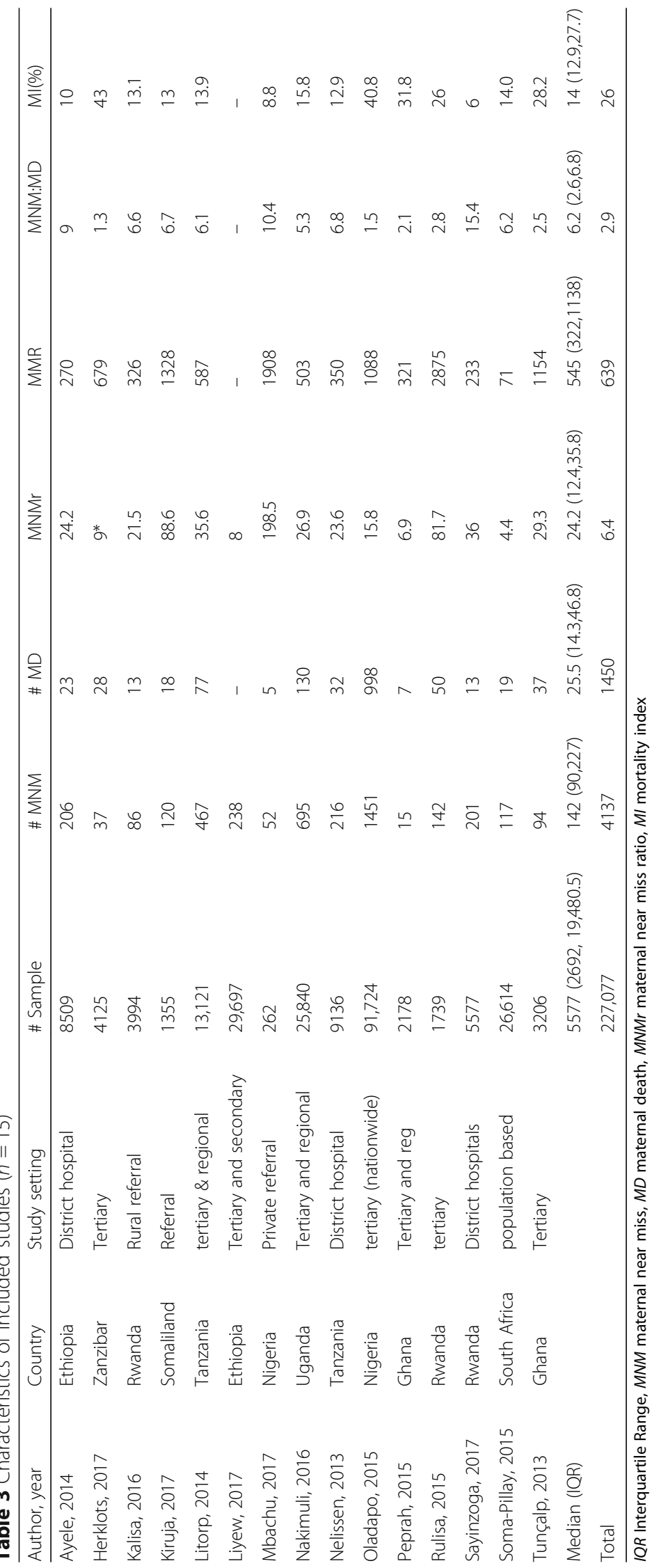


Table 4 Applicability of the WHO MNM criteria and suggested adaptations

\begin{tabular}{|c|c|c|c|}
\hline Study & Hospital type & Reported challenges or removed criteria & Adaptations made \\
\hline Ayele, 2014, Ethiopia & District & Not all WHO near miss criteria were available & $\begin{array}{l}\text { Reported as possible limitation only. No } \\
\text { adaptation made or suggested }\end{array}$ \\
\hline Litorp, 2014, Tanzania & $\begin{array}{l}\text { Tertiary and } \\
\text { secondary }\end{array}$ & $\begin{array}{l}\text { Due to limited resources, some laboratory- and } \\
\text { management-based criteria were not applicable } \\
\text { (not specified) }\end{array}$ & $\begin{array}{l}\text { None. But it was reported as a limitation } \\
\text { for possible under-estimation especially at } \\
\text { the regional hospital }\end{array}$ \\
\hline Nelissen, 2013, Tanzania & District & $\begin{array}{l}\text { Removed: PaO2/FiO2 }<200 \mathrm{mmHg} \text {; creatinine } \\
\geq 300 \mu \mathrm{mol} / \mathrm{l} \text { or } \geq 3.5 \mathrm{mg} / \mathrm{dl} \text {; bilirubin } \\
>100 \mu \mathrm{mol} . \mathrm{l} \text { or }>6.0 \mathrm{mg} / \mathrm{dl} ; \mathrm{pH}<7.1 \text {; lactate } \\
>5 \mathrm{mEq} / \mathrm{ml} \text { l loss of consciousness and } \\
\text { ketoacids in urine; use of continuous } \\
\text { vasoactive drugs; dialysis for acute renal failure }\end{array}$ & $\begin{array}{l}\text { Included additionally eclampsia, uterine } \\
\text { rupture, sepsis or severe systemic infection, } \\
\text { admission to intensive care unit, reducing } \\
\text { threshold of blood for transfusion from } \geq 5 \\
\text { units to } \geq 1 \text { (Haydom Hospital criteria) }\end{array}$ \\
\hline Rulisa, 2015, Rwanda & Tertiary & $\begin{array}{l}\text { In most cases, it was impossible to meet the } \\
\text { full WHO criteria because most of the } \\
\text { laboratory tests used to define those events, } \\
\text { were not performed at the hospital }\end{array}$ & $\begin{array}{l}\text { Patients were include if they had severe } \\
\text { maternal complications (not specified) or } \\
\text { admitted to intensive care unit }\end{array}$ \\
\hline Tuncalp 2013, Ghana & Tertiary & $\begin{array}{l}\text { Although laboratory testing was available, } \\
\text { often the markers were not requested on } \\
\text { time or at all owing to the urgency of the } \\
\text { management of these women. }\end{array}$ & No adaptation was made \\
\hline Herklots 2017, Zanzibar & Tertiary & $\begin{array}{l}\text { Some of the markers were not applicable to } \\
\text { the setting especially laboratory criteria }\end{array}$ & $\begin{array}{l}\text { Lowered threshold of blood transfusion } \\
\text { from } \geq 5 \text { units to } \geq 5 \text { units transfused or } \\
\text { ordered but not entirely given }\end{array}$ \\
\hline Kalisa, 2016, Rwanda & District & $\begin{array}{l}\text { Reported as not available: } \mathrm{PaO} 2 / \mathrm{FiO} 2 \\
<200 \mathrm{mmHg} \text {; } \mathrm{pH}<7.1 \text {; lactate }>5 \mathrm{mEq} / \mathrm{ml} \text {; } \\
\text { ketoacids in urine; dialysis for acute renal } \\
\text { failure }\end{array}$ & $\begin{array}{l}\text { Additionally included: eclampsia, uterine } \\
\text { rupture, sepsis or severe systemic infection; } \\
\text { admission to intensive care unit (Ruhengeri } \\
\text { hospital criteria) }\end{array}$ \\
\hline Sayinzoga, 2017, Rwanda & District & The WHO criteria adapted in the Haydom study was used & Used Haydom Hospital criteria \\
\hline
\end{tabular}

and ability to make an appropriate diagnosis [57, 58]. Transfusion of five or more units of blood, and diagnosis of MNM based on the majority of the WHO laboratory-based criteria are unlikely in most sub-Saharan Africa settings. As the ultimate goal of studying MNM is to improve quality of obstetric care $[2,6]$, this aim should not be compromised by the need to compare findings across studies.

To our knowledge, this is the first review to systematically synthesize the applicability of the WHO MNM criteria in sub-Saharan Africa. The use of WHO MNM criteria in sub-Saharan Africa is compounded by the need for having uniform criteria and limitations to apply some parameters related to laboratory- and management- based criteria. These considerations are affecting the use of the original criteria or making local adaptations based on the researchers' judgement [29]-which may result in several different adaptations.

Locally adapted criteria may enable researchers to get a better estimate of the prevalence of MNM [59], but such findings could not be compared with other studies which used different criteria [12]. Similarly, using the WHO criteria is essential for having comparable findings across studies. But this may underestimate the true burden of cases as it only picks the most severe cases $[53,60]$.

\section{Conclusion}

This review showed that the WHO MNM tool is not uniformly applied in sub-Saharan Africa. In eight studies challenges for using the WHO MNM tool were reported. Limited supply of blood and lack of infrastructure for performing some of the WHO laboratory-based criteria were the major challenges reported. There is a need to have a common tool for use in sub-Saharan Africa to avoid different adaptations because of the limited applicability of the WHO MNM tool.

\section{Additional file}

Additional file 1: Search strategy. The list of data bases searched and keywords used for searching. (DOC $62 \mathrm{~kb}$ )

\section{Abbreviations}

IQR: Interquartile range; MD: Maternal Death; MI: Mortality Index; MMR: Maternal Mortality Ratio; MNM: Maternal Near Miss; SRDR: Systematic Review Data Repository; WHO: World Health Organization

\section{Acknowledgements}

We want to thank University Medical Centre Groningen librarian who helped us in the development of the search strategy. We also want to thank the Dutch organization for internationalization in education for funding this study. 


\section{Funding}

AKT received a stipend from the Dutch organization for internationalization in education (Nuffic) in the form of a PhD study. The funders have no role in the design, data collection, analysis or the decision to publish.

\section{Availability of data and materials}

All data underlying the findings in the study are included in the manuscript. Additional data are available from the corresponding author on reasonable request.

\section{Authors' contributions}

AKT, SS, JZ, TVdA, JVR and JS conceived the review. AKT and TLT screened articles and extracted data. AKT drafted the manuscript, which was revised by TLT, JZ, SS, JvR, TVdA, and JS. All authors approved the final version for submission.

\section{Ethics approval and consent to participate}

Not applicable

\section{Consent for publication}

Not applicable

\section{Competing interests}

JVR is section editor while TVDA and JS are associate editors in BMC Pregnancy and Childbirth. All other authors have no competing interests.

\section{Publisher's Note}

Springer Nature remains neutral with regard to jurisdictional claims in published maps and institutional affiliations.

\section{Author details}

${ }^{1}$ School of Nursing and Midwifery, College of Health and Medical Sciences, Haramaya University, Dire Dawa, Ethiopia. ²Department of Obstetrics and Gynecology, University Medical Centre Groningen, University of Groningen, Hanzeplein 1, 9700 RB, P.O.B, 30001 Groningen, The Netherlands. ${ }^{3}$ Department of Obstetrics and Gynecology, Leeuwarden Medical Center, Leeuwarden, The Netherlands. ${ }^{4}$ Department of Obstetrics and Gynaecology, Leiden University Medical Center, Leiden, the Netherlands. ${ }^{5}$ Athena Institute, Vrije Universiteit Amsterdam, Amsterdam, The Netherlands. ${ }^{6}$ Department of Obstetrics and Gynecology, Deventer Ziekenhuis, Deventer, The Netherlands. ${ }^{7}$ Department of Health Sciences, Global Health, University Medical Centre Groningen, University of Groningen, Groningen, The Netherlands.

Received: 25 September 2018 Accepted: 19 February 2019 Published online: 26 February 2019

\section{References}

1. Pattinson RC, Hall M. Near misses: a useful adjunct to maternal death enquiries. Br Med Bull. 2003;67:231-43.

2. World Health Organization. Beyond the numbers: reviewing maternal deaths and complications to make pregnancy safer. Geneva: World Health Organization; 2004

3. Say L, Souza JP, Pattinson RC. WHO working group on maternal mortality and morbidity classifications. Maternal near miss--towards a standard tool for monitoring quality of maternal health care. Best Pract Res Clin Obstet Gynaecol. 2009;23(3):287-96.

4. Chhabra P. Maternal near miss: an indicator for maternal health and maternal care. Indian J Community Med. 2014;39(3):132-7.

5. Kalhan M, Singh S, Punia A, Prakash J. Maternal near-miss audit: lessons to be learnt. Int J Appl Basic Med Res. 2017;7(2):85-7.

6. World Health Organization. Evaluating the quality of care for severe pregnancy complications: the WHO near-miss approach for maternal health. 2011.

7. Ronsmans C, Filippi V. Reviewing severe maternal morbidity: learning fromsurvivors of life-threatening complications. In: Beyond the numbers: Reviewingmaternal deaths and complications to make pregnancy safer complications. Geneva: World Health Organization; 2004.

8. Spector J. Practical criteria for maternal near miss needed for low-income settings. Lancet. 2013;382(9891):504-5.
9. Nelissen E, Mduma E, Broerse J, Ersdal H, Evjen-Olsen B, van Roosmalen J, Stekelenburg J. Applicability of the WHO maternal near miss criteria in a low-resource setting. PLoS One. 2013;8(4):e61248.

10. van den Akker T, Beltman J, Leyten J, Mwagomba B, Meguid T, Stekelenburg J, van Roosmalen J. The WHO maternal near miss approach: consequences at Malawian District level. PLoS One. 2013:8(1):e54805.

11. Kalisa R, Rulisa S, van den Akker T, van Roosmalen J. Maternal near miss and quality of care in a rural Rwandan hospital. BMC Pregnancy Childbirth. 2016;16:324.

12. Say L, Pattinson RC, Gulmezoglu AM. WHO systematic review of maternal morbidity and mortality: the prevalence of severe acute maternal morbidity (near miss). Reprod Health. 2004;1(1):3 -4755-1-3.

13. Tuncalp O, Hindin MJ, Souza JP, Chou D, Say L. The prevalence of maternal near miss: a systematic review. BJOG. 2012;119(6):653-61.

14. Kaye DK, Kakaire O, Osinde MO. Systematic review of the magnitude and case fatality ratio for severe maternal morbidity in sub-Saharan Africa between 1995 and 2010. BMC Pregnancy Childbirth. 2011;11:65 2393-11-65.

15. Filippi V, Ronsmans C, Gohou V, Goufodji S, Lardi M, Sahel A, et al. Maternity wards or emergency obstetric rooms? Incidence of near-miss events in African hospitals. Acta Obstet Gynecol Scand. 2005:84(1):11-6.

16. Moher D, Liberati A, Tetzlaff J, Altman DG. Preferred reporting items for systematic reviews and meta-analyses: the PRISMA statement. J Clin Epidemiol. 2009;62(10):1006-12.

17. Covidence systematic review software, Veritas Health Innovation, Melbourne, Australia. Available at www.covidence.org.

18. Borghi J, Hanson K, Acquah CA, Ekanmian G, Filippi V, Ronsmans C, et al. Costs of near-miss obstetric complications for women and their families in Benin and Ghana. Health Policy Plan. 2003;18(4):383-90.

19. Filippi V, Ganaba R, Baggaley RF, Marshall T, Storeng KT, Sombie I, et al. Health of women after severe obstetric complications in Burkina Faso: a longitudinal study. Lancet. 2007:370(9595):1329-37.

20. Furuta M, Sandall J, Bick D. Women's perceptions and experiences of severe maternal morbidity--a synthesis of qualitative studies using a metaethnographic approach. Midwifery. 2014;30(2):158-69.

21. Norhayati MN, Nik Hazlina NH, Asrenee AR, Sulaiman Z. The experiences of women with maternal near miss and their perception of quality of care in Kelantan, Malaysia: a qualitative study. BMC Pregnancy Childbirth. 2017; 17(1):189 -017-1377-6.

22. Silva DV, Silveira Mde F, Gomes-Sponholz FA. Experiences with severe maternal morbidity: a qualitative study on the perception of women. Rev Bras Enferm. 2016:69(4):662-8.

23. Storeng KT, Murray SF, Akoum MS, Ouattara F, Filippi V. Beyond body counts: a qualitative study of lives and loss in Burkina Faso after 'near-miss' obstetric complications. Soc Sci Med. 2010;71(10):1749-56.

24. Storeng KT, Drabo S, Ganaba R, Sundby J, Calvert C, Filippi V. Mortality after near-miss obstetric complications in Burkina Faso: medical, social and health-care factors. Bull World Health Organ. 2012;90(6):418-425B.

25. Systematic Review Data Repository. Available at https://srdr.ahrq.gov/.

26. Estabrooks CA, Cummings GG, Olivo SA, Squires JE, Giblin C, Simpson N. Effects of shift length on quality of patient care and health provider outcomes: systematic review. Qual Saf Health Care. 2009;18(3):181-8.

27. Squires JE, Estabrooks CA, Gustavsson P, Wallin L. Individual determinants of research utilization by nurses: a systematic review update. Implement Sci. 2011:6(1):1.

28. de Vet HC, de Bie RA, van der Heijden GJ, Verhagen AP, Sijpkes P, Knipschild PG. Systematic reviews on the basis of methodological criteria. Physiotherapy. 1997;83(6):284-9.

29. Litorp H, Kidanto HL, Roost M, Abeid M, Nystrom L, Essen B. Maternal nearmiss and death and their association with caesarean section complications: a cross-sectional study at a university hospital and a regional hospital in Tanzania. BMC Pregnancy Childbirth. 2014;14:244 -2393-14- 244

30. Oladapo O, Adetoro O, Ekele B, Chama C, Etuk S, Aboyeji A, et al. When getting there is not enough: a nationwide cross-sectional study of 998 maternal deaths and 1451 near-misses in public tertiary hospitals in a lowincome country. BJOG Int J Obstet Gynaecol. 2016;123(6):928-38.

31. Peprah N. Severe maternal morbidity and associated factors in Suntreso and Kumasi south government hospitals, Ashanti region. Ghana: University of Ghana; 2015.

32. Nakimuli A, Nakubulwa S, Kakaire O, Osinde MO, Mbalinda SN, Nabirye RC, et al. Maternal near misses from two referral hospitals in Uganda: a prospective cohort study on incidence, determinants and prognostic factors. BMC Pregnancy Childbirth. 2016;16:24 -016-0811-5. 
33. Soma-Pillay P, Pattinson RC, Langa-Mlambo L, Nkosi BS, Macdonald AP. Maternal near miss and maternal death in the Pretoria academic complex, South Africa: a population-based study. S Afr Med J. 2015;105(7):578-63.

34. Sayinzoga F, Bijlmakers $L$, van der Velden K, van Dillen J. Severe maternal outcomes and quality of care at district hospitals in Rwanda- a multicentre prospective case-control study. BMC Pregnancy Childbirth. 2017;17(1):394 -017-1581-4.

35. Liyew EF, Yalew AW, Afework MF, Essen B. Incidence and causes of maternal near-miss in selected hospitals of Addis Ababa. Ethiopia PLoS One. 2017;12(6):e0179013

36. Ayele B, Amenu D, Gurmessa A. Prevalence of Maternal Near Miss and Maternal Death in Atat Hospital, Ethiopia. J Womens Health Issues Care 3 2014, 6:2.

37. Nelissen EJ, Mduma E, Ersdal HL, Evjen-Olsen B, van Roosmalen JJ, Stekelenburg J. Maternal near miss and mortality in a rural referral hospital in northern Tanzania: a cross-sectional study. BMC Pregnancy Childbirth. 2013;13:141 -2393-13-141.

38. Rulisa S, Umuziranenge I, Small M, van Roosmalen J. Maternal near miss and mortality in a tertiary care hospital in Rwanda. BMC Pregnancy Childbirth. 2015;15:203 -015-0619-8.

39. Tuncalp O, Hindin MJ, Adu-Bonsaffoh K, Adanu RM. Assessment of maternal near-miss and quality of care in a hospital-based study in Accra. Ghana Int Gynaecol Obstet. 2013;123(1):58-63.

40. Herklots T, van Acht L, Meguid T, Franx A, Jacod B. Severe maternal morbidity in Zanzibar's referral hospital: measuring the impact of in-hospital care. PLoS One. 2017;12(8):e0181470.

41. Kiruja J, Osman F, Egal JA, Essen B, Klingberg-Allvin M, Erlandsson K. Maternal near-miss and death incidences - frequencies, causes and the referral chain in Somaliland: a pilot study using the WHO near-miss approach. Sex Reprod Healthc. 2017;12:30-6.

42. Mbachu II, Ezeama C, Osuagwu K, Umeononihu OS, Obiannika C, Ezeama N. A cross sectional study of maternal near miss and mortality at a rural tertiary centre in southern nigeria. BMC Pregnancy Childbirth. 2017;17(1):251 -017-1436-z.

43. Neto AO, Parpinelli M, Cecatti J, Souza J, Sousa M. Sequential organ failure assessment (SOFA) score for evaluating organ failure and outcome in severe maternal morbidity in obstetric intensive care. In Document presented at the WHO Working Group on Maternal Mortality and Morbidity Classification. Edited by Anonymous World Health Organization; 2008:

44. Vincent JL, Moreno R, Takala J, Willatts S, De Mendonca A, Bruining H, et al. The SOFA (Sepsis-related organ failure assessment) score to describe organ dysfunction/failure. On behalf of the working group on Sepsis-related problems of the European Society of Intensive Care Medicine. Intensive Care Med. 1996;22(7):707-10.

45. Vincent $\mathrm{J}$, de Mendonca A, Cantraine F, Moreno R, Takala J, Suter PM, et al. Use of the SOFA score to assess the incidence of organ dysfunction/failure in intensive care units: results of a multicenter, prospective study. Working group on "sepsis-related problems" of the European Society of Intensive Care Medicine. Crit Care Med. 1998;26(11):1793-800.

46. Cecatti JG, Souza JP, Oliveira Neto AF, Parpinelli MA, Sousa MH, Say L, et al. Pre-validation of the WHO organ dysfunction based criteria for identification of maternal near miss. Reprod Health. 2011:8:22 -4755-8-22

47. Oliveira Neto AF, Parpinelli MA, Costa ML, Souza RT, Rikbeiro do Valle C, Cecatti JG. Exploring Epidemiological Aspects, Distribution of WHO Maternal Near Miss Criteria, and Organ Dysfunction Defined by SOFA in Cases of Severe Maternal Outcome Admitted to Obstetric ICU: A Cross-Sectional Study. Biomed Res Int 2018, 2018.

48. Souza JP, Say L, Gulmezoglu M. Practical criteria for maternal near miss needed for low-income settings - Authors' reply. Lancet. 2013;382(9891):505 $-6736(13) 61711-0$

49. Tura AK, Stekelenburg J, Scherjon SA, Zwart J, van den Akker T, van Roosmalen J, et al. Adaptation of the WHO maternal near miss tool for use in sub-Saharan Africa: an International Delphi study. BMC Pregnancy Childbirth. 2017;17(1):445 -017-1640-x

50. Gebrehiwot $Y$, Tewolde BT. Improving maternity care in Ethiopia through facility based review of maternal deaths and near misses. Int J Gynaecol Obstet. 2014;127(Suppl 1):S29-34

51. Berhane G, Gessessew A, van Roosmalen J, van den Akker T. Obstetric near miss and maternal death: the case of Ayder teaching hospital, Mekelle, Ethiopia. Ethiopian J Reprod Health. 2012;6(1):56-63.
52. Nyamtema $A S$, de Jong $A B$, Urassa DP, van Roosmalen J. Using audit to enhance quality of maternity care in resource limited countries: lessons learnt from rural Tanzania. BMC Pregnancy Childbirth. 2011;11:94 -2393-11-94.

53. Witteveen $\mathrm{T}$, de Koning I, Bezstarosti $\mathrm{H}$, van den Akker $\mathrm{T}$, van Roosmalen J, Bloemenkamp KW. Validating the WHO maternal near miss tool in a highincome country. Acta Obstet Gynecol Scand. 2016;95(1):106-11.

54. Bates I, Chapotera GK, McKew S, van den Broek N. Maternal mortality in sub-Saharan Africa: the contribution of ineffective blood transfusion services. BJOG. 2008;115(11):1331-9.

55. Roberts DJ, Field S, Delaney M, Bates I. Problems and approaches for blood transfusion in the developing countries. Hematol Oncol Clin North Am. 2016;30(2):477-95

56. Bates I, Hassall O, Mapako T. Transfusion research priorities for blood services in sub-Saharan Africa. Br J Haematol. 2017;177(6):855-63.

57. Fokom-Domgue J, Noubiap JJ. Diagnosis of hypertensive disorders of pregnancy in sub-Saharan Africa: a poorly assessed but increasingly important issue. J Clin Hypertens (Greenwich). 2015;17(1):70-3.

58. Ordi J, Ismail MR, Carrilho C, Romagosa C, Osman N, Machungo F, et al. Clinico-pathological discrepancies in the diagnosis of causes of maternal death in sub-Saharan Africa: retrospective analysis. PLoS Med. 2009;6(2): e1000036.

59. Tura AK, Zwart J, Van Roosmalen J, Stekelenburg J, Van Den Akker T, Scherjon S. Severe maternal outcomes in eastern Ethiopia: application of the adapted maternal near miss tool. PLoS One. 2018;13(11):e0207350.

60. Witteveen T, Bezstarosti H, de Koning I, Nelissen E, Bloemenkamp KW, van Roosmalen J, et al. Validating the WHO maternal near miss tool: comparing high- and low-resource settings. BMC Pregnancy Childbirth. 2017;17(1):194 $-017-1370-0$
Ready to submit your research? Choose BMC and benefit from:

- fast, convenient online submission

- thorough peer review by experienced researchers in your field

- rapid publication on acceptance

- support for research data, including large and complex data types

- gold Open Access which fosters wider collaboration and increased citations

- maximum visibility for your research: over $100 \mathrm{M}$ website views per year

At $\mathrm{BMC}$, research is always in progress.

Learn more biomedcentral.com/submissions 